Laboratorio de Arte,4-1991 http://dx.doi.org/10.12795/LA.1991.i04.16

\title{
XANADÚ COMO SÍMBOLO MATERIAL DEL CIUDADANO KANE
}

\author{
por Carmen Aguayo Zarracayo
}

\begin{abstract}
Xanadú no es simplemente la mansión que Charles Foster Kane se mandara construir. El análisis de su arquitectura revela hasta qué punto ésta es utilizada como medio expresivo para sugerir visualmente la personalidad de Kane.
\end{abstract}

Xanadu is not merely the mansion built for Charles Foster Kane. An analysis of its architecture reveals to what extent it was designed as a visual expression of Kane's personality.

Robert L. Carringer en su libro Cómo se hizo Ciudadano Kane apunta ${ }^{1}$ posibles influencias del comienzo de Rebeca (Rebecca, 1940), de Alfred Hitchcock, en la primera secuencia de Ciudadano Kane:

"La idea de hacer que la cámara entrara lentamente en una propiedad en estado ruinoso, así como la utilización de un monograma, pudo haber sido inspirada por Rebecca, que empezó a verse en Hollywood, en proyecciones previas al estreno, en diciembre de 1939."

Esta influencia es algo evidente. No sólo los dos filmes comienzan con el acercamiento de la cámara a una propiedad, Manderley en el caso de Rebeca y Xanadú en el de Ciudadano Kane, sino que terminan con la operación inversa, con el alejamiento de la cámara de una propiedad en ambos casos en estado de .

1. CARRINGER, Robert L.: Cómo se hizo Ciudadano Kane. Ultramar editores. Barcelona, 1987, p. 38. 
abandono. En cuanto al otro punto al que se refiere Carringer, hay que decir que en Rebeca se utilizaba el monograma "R" para transmitir cómo Manderley y todo lo que se albergaba en ella, no sólo las cosas sino también las personas, pertenecían a Rebeca, incluso después de muerta; es este mismo sentido el que se quiere dar a entender con el monograma " $K$ " que aparece en la verja de entrada a Xanadú: el castillo y todo lo que cobija en su interior pertenece a Kane; al traspasar la verja, entramos en su feudo, el último reducto del poder de Kane tras el fracaso con el mundo exterior.

Existen, sin embargo, otros aspectos en Ciudadano Kane donde es fácil encontrar una serie de similitudes con Rebeca, como son los paralelismos que se pueden establecer entre Manderley y Xanadú, poseedoras de tal entidad dentro del filme que pueden ser consideradas como un personaje más. Ambas están aisladas, rodeadas por la naturaleza, no existe ninguna otra construcción a su alrededor y sus localizaciones geográficas las conocemos de forma imprecisa: Manderley en la campiña inglesa y Xanadú en el desierto de la costa del golfo de Florida ${ }^{2}$.

Tratamiento aparte merece un último punto donde de nuevo aparecen coincidencias entre Rebeca y Ciudadano Kane. Nos referimos a la ensoñación y romanticismo que Rebeca lograba recrear y que Ciudadano Kane repite en su secuencia inicial. Rebeca comienza con la frase "Ayer soñé que volvía a Manderley", por lo que las primeras imágenes del filme estaban envueltas en un clima de calma e irrealidad, potenciado por el uso de maquetas para el camino y la mansión, que hiciera posible relacionarlas con lo onírico: la atmósfera brumo$\mathrm{sa}$, la noche, la casa en ruinas. Todo esto se repite en el inicio de Ciudadano Kane: la escena queda envuelta en la bruma y se desarrolla de noche, ayudando a rodear de misterio la figura de Kane. Una alambrada con un cartel de prohibido el paso precisa los límites de Xanadú, la cámara tomará este punto de partida para acercarse cada vez más al castillo hasta entrar en la habitación de Kane; en su recorrido nos irá mostrando la verja de entrada con el anagrama "K", una jaula de monos, góndolas sobre un lago artificial, arquitecturas abandonadas y resto de vegetación de lo que tuvo que ser un fantástico jardín y donde ahora sólo reina la soledad y la dejadez, algo que ya existía la primera vez que aparecía Manderley en Rebeca, y que aquí se utiliza para reflejar el ocaso final de Kane. También se muestran vistas lejanas de un Xanadú que nunca se llegó a construir realmente, aunque no se trataba de una maqueta como en Manderley, sino que la ilusión óptica se conseguía mediante un dibujo sobre cristal, creando una atmósfera de fantasía mayor, si cabe, que en Rebeca.

2. TRUFFAUT, François: El cine segı́n Hitchcock. El libro de bolsillo, Alianza Editorial. Madrid, 1985, pp. 110-111. 
Es cierto que el tratamiento romántico dado al comienzo de Ciudadano Kane está influenciado por Rebeca, pero no hay que olvidar que en la misma época aparecieron otras películas que participaban en mayor o menor medida del mismo tratamiento, tal es el caso de Jezabel (Jezebel, 1938) -en particular, la última escena del filme, donde Bette Davis decidía acompañar a Henry Fonda en su viaje final a la isla de las víctimas de la fiebre amarilla- y Cumbres Borrascosas (Wutering Heights, 1939), ambas de William Wyler, siendo esta última, curiosamente, fotografiada por Greg Toland, el operador de cámara de Ciudadano Kane, y dondé ya utilizó la profundidad de campo popularizada más tarde por Ciudadano Kane.

Fuera ya de posibles influencias de uno u otro filme, lo que sí queda claro es que las primeras imágenes de Ciudadano Kane remiten constantemente a las características del Romanticismo del siglo XIX:

el gusto por lo prohibido

el gusto por las ruinas y lo desolador la verja, la alambrada;

Xanadú, nunca terminado de construir, y prácticamente abandonado durante los últimos días de Kane, acabará siendo tan sólo una sombra de lo que fue;

el gusto por lo exótico y lo extravagante la suma de los estilos y los países en la arquitectura; el zoológico; las góndolas en el lago artificial; la colección de estatuas... resultado del capricho de Kane;

el gusto por lo medieval

la imaginación y lo onírico

el individualismo y el triunfo del yo las vidrieras, arcos ojivales, matacanes, almenas... En Xanadú, tomado como totalidad, predomina la arquitectura gótica;

Xanadú es como un castillo de hadas, ¿o es de terror?, con ventanas góticas $y$ torreones, situado sobre una montaña envuelta por la bruma;

Xanadú es el símbolo del poder de un solo hombre: Charles Foster Kane. 
Es curioso observar cómo Xanadú sólo aparece al principio y al final del filme, de modo que podemos establecer la estructura de Ciudadano Kane de la siguiente forma:

1. La cámara se acerca a Xanadú. Exterior.

2. Kane visto por los que le conocieron. No aparece Xanadú.

3. Interior de Xanadú. La cámara se aleja.

Esta estructura no sólo está condicionada por el argumento, sino que va más allá, ya que partiendo de que una casa es el reflejo de sus habitantes, Xanadú se erige como el símbolo material de la vida y la personalidad de Kane, y es utilizado como metáfora dentro del lenguaje cinematográfico, tanto para expresar visualmente su figura pública como sus sentimientos.

Por esto, no es una casualidad que el filme comience con varios fundidos encadenados que nos van acercando al castillo, ya que al mismo tiempo se está produciendo nuestra primera aproximación a Kane a través de una serie de elementos necesarios para intuir cómo es el morador de Xanadú: se nos presenta un paraje desolador donde la oscuridad y la bruma lo invaden todo, creando un ambiente lóbrego y sombrío; el abandono de Xanadú va parejo a la decadencia de su dueño y a la soledad física de sus últimos años, porque en realidad siempre estuvo solo, nadie consiguió jamás conocer su interior ni compartir sus sentimientos; la calma y la ausencia de vida de los alrededores del castillo se relacionan con la muerte de Kane; la alambrada y la verja de entrada con el anagrama "K" nos habla de un hombre solitario y encerrado en sí mismo; la ubicación de Xanadú sobre una montaña tiene diferentes lecturas, desde el aislamiento de Kane o a cómo, orgulloso y siempre creyéndose por encima de los demás, consiguió que su dinero y su poder en la prensa le llevaran al vértice de la sociedad norteamericana; sin embargo, del mismo modo que Xanadú nunca se terminó de construir, Kane quedó inconcluso, fracasó en su vida, pública y privada. Nunca alcanzó la felicidad.

Xanadú, inspirado en la mansión de San Simeón de William Randolph Hearst ${ }^{3}$, tiene su origen en el guión de Orson Welles y Herman J. Mankiewicz para Ciudadano Kane: "The castle itself, an enormous pile, compounded of several genuine castle, of European origin, of varying architecture...".

Se trataba de crear un gran castillo sobre una montaña capaz de evocar los de la vieja Europa, de esta forma se parangonaba a Kane con la nobleza, inexistente en América, pero donde se le puede incluir simbólicamente dada su fortuna y el lugar que ocupó dentro de la sociedad; al mismo tiempo se lograba otro efecto:

3. CARRINGER, Robert L.: Cómo se hizo Ciudadano Kane. Ultramar editores. Barcelona, 1987, p. 73. 
asociar a Kane con el feudalismo y, por ende, pensar en Kane como un señor feudal, y es que, no obstante, siempre supo mover los hilos de las personas que tuvo a su alrededor.

Xanadú tenía que ser el reflejo del poder conseguido por Kane, de su grandeza y sus deseos de megalomanía. De ahí la monumentalidad reinante en el castillo que abruma y fascina al espectador. Esto era la verdadera intención y por ello no importaba si en busca de este fin se incurría en falta de rigor o en alguna incongruencia, ya que no existía el miedo a caer en lo pretencioso, sino que se buscaba intencionadamente para manifestar la importancia del dueño de Xanadú.

El departamento de arte de la RKO, con Van Nest Polglase a su frente ${ }^{4}$, buscó inspiración en la arquitectura europea a través de los archivos de los estudios; sin embargo, precisar el origen de cada uno de los elementos que conforman el exterior del castillo resulta algo aventurado: una torre, igual a la del Campanile de San Marcos de Venecia, acompañada de otras de su mismo perfil; un pórtico que nos recuerda al corredor vasariano del Palacio Pitti; un chapitel asociable al barroco castellano del primer tercio del siglo XVII e incluso al final del filme aparece una parte que tiene demasiadas semejanzas con la fachada de la iglesia de San Zacarías de Venecia.

Con respecto a este eclecticismo, no hay que olvidar que cuando se nos muestra una vista general de Xanadú, lo que vemos en realidad es un dibujo sobre cristal, con lo cual la suma de elementos arquitectónicos de partes de edificios, ficticios o reales, se hace más fácil. Y decimos suma porque lejos de constituir un estilo híbrido, percibimos un conjunto armonioso, ya que existe un componente aglutinador: lo medieval. No sólo por el uso de ojivas, rosetones, matacanes y almenas, sino porque incluso lo que no pertenece a este período se puede considerar dentro de él: las torres o el almohadillado y el arco de medio punto del pórtico no están tan lejos de lo medieval.

Xanadú dibuja la silueta de un castillo medieval, siempre bajo el condicionante de la fantasía de los directores de arte de los estudios, incluyendo la característica gótica de la verticalidad, potenciada por su situación sobre una montaña, lo que se relaciona, de nuevo, con el dominio que Kane ejerció sobre los demás, con la importancia y el lugar predominante que logró ocupar.

Si buscáramos en la arquitectura real un edificio con una silueta semejante a Xanadú, habría que mencionar, por ejemplo, el Alcázar de Segovia o el castillo de Neuschwanstein, que ubicados sobre una montaña evocan con sus torreones los castillos de los cuentos de hadas. Con Neuschwanstein, Xanadú guarda otros paralelismos además de los referentes a su arquitectura y que son extensibles a

4. Id. ib. Para una información completa sobre el proceso de formación del trabajo artístico en Ciudadano Kane, véase especialmente pp. 59-74. 
los que podemos establecer entre Luis de Baviera, artífice de la construcción de Neuschwanstein, y Charles Foster Kane:

Luis II de Baviera, el rey loco, accede al trono con diecinueve años, obligado por la muerte de su padre. Kane desde su infancia se enfrenta con responsabilidades que culminan cuando a los veinticinco años toma plena posesión de su fortuna.

El reinado de Luis II no fue brillante en política; se refugió en las artes, mandando edificar castillos repletos de toda la magnificencia que podamos imaginar. Tampoco Kane consiguió triunfar plenamente en su faceta pública, su carrera política se truncó de repente, y casi al final de su vida se vio obligado a vender el periódico; sin embargo, su deseo de grandeza le llevó a construir "la finca de recreo más grande del mundo".

En Neuschwanstein predomina el recuerdo del gótico, estilo que como hemos visto está presente en Xanadú. Neuschwanstein, al igual que Xanadú, nunca se terminó de construir.

Hasta ahora hemos analizado la imagen que se nos ha dado de Xanadú en la secuencia inicial de Ciudadano Kane, pero también aparece en el noticiario sobre Charles F. Kane que sigue a esta secuencia. Como parte del castillo se nos presentan vistas de edificios existentes en la realidad: distintas partes de una fortaleza medieval, una portada plateresca, jardines que recuerdan al barroco francés o austriaco o vistas áreas que hacen pensar en los palacios renacentistas franceses; frente a esto, lo que aparece en mayor número son los pertenecientes a edificios barrocos hispanoamericanos, quizás debido a la localización de Xanadú en la costa de Florida.

Lo que llama la atención es que estas vistas no se corresponden en absoluto con la visión que anteriormente se nos ha dado de Xanadú: un castillo sobre una montaña, aislado, sin otro edificio a su alrededor. La respuesta hay que buscarla en el deseo de magnificar la dimensión de Kane a través de la presentación de edificios reales, y en la búsqueda de este fin no les importa caer en más incongruencias; aunque bien es verdad que la elección de estas construcciones para el noticiario pudo estar condicionado por la falta de presupuesto a la hora de elevar un decorado o realizar unas maquetas para unas tomas que sólo duraban unos minutos.

No sólo no se tiene pudor alguno en mostrar estos edificios como parte de Xanadú o en introducir en el mismo noticiario un dibujo del castillo con una arquitectura "pseudo hindú" que se contradice también con todo lo anterior, sino que además vienen acompañados de una voz en off con comentarios de este estilo:

"Lo que contiene el palacio de Xanadú, cuadros, pinturas, estatuas, hasta las propias piedras de otros palacios, forman colecciones tan gran- 
des que jamás podrán ser catalogadas ni valoradas; llenarían diez museos en todo el mundo."

"Igual que los faraones, el propietario de Xanadú dejó muchos testimonios en piedra para marcar su tumba. Después de las pirámides, Xanadú es el edificio más costoso que un hombre haya construido para sí mismo."

Y es que nada es suficiente para engrandecer a Kane, para mostrar cuál fue su poderío económico, político y social, hasta qué punto fue envidiado y adorado por todos. La exageración lo marca todo y, con ella, la admiración del espectador hacia Kane queda garantizada.

El exterior de Xanadú, que aparece en la secuencia inicial y en el noticiario, ha sido utilizado para acercarnos a Kane, primando los aspectos que aluden a su imagen pública, la parcela que todo el mundo puede conocer al tratarse de un personaje famoso. Tras este prólogo que sirve de presentación a la figura de Kane, entramos en la verdadera estructura del filme: las versiones que de la vida y de la personalidad de Kane se dan a través de las personas que le conocieron. Con todo esto, el espectador está en condiciones de abarcar una parcela de Kane que nunca nadie llegó a comprender: su interior. Por ello no es casual que al final del filme la trama se concentre en el interior de Xanadú, ya que éste es el reflejo de un Kane de alma atormentada y personalidad frustrada en el declive de su vida.

La parte principal del interior de Xanadú es el gran salón, equivalente al salón noble o salón del trono de los castillos medievales. Diseñado como un enorme espacio vacío donde apenas hay muebles u objetos suntuarios, lo que no es comprensible si consideramos la fortuna de Kane y la envergadura de un palacio como Xanadú. El porqué estaría en razones de índole económica ${ }^{5}$; sin embargo, esto aumenta más aún la espacialidad del salón, consiguiendo crear un espacio frío e inhóspito que refleja el alejamiento entre Susan y Kane y de éste con el mundo. En Xanadú, Kane se rodeó de piedras, pero estaba solo como lo estuvo toda su vida.

Los elementos arquitectónicos que aparecen en el gran salón continúan con el eclecticismo del exterior del palacio: la chimenea ${ }^{6}$, construida especialmente para el filme, es tan descomunal en tamaño que es capaz de empequeñecer la figura de Kane y transmitir cómo su importancia ha disminuido, cómo ha perdido su poder. La profusión de ornamento de la chimenea nos remite a las chimeneas de los palacios manieristas franceses, si bien su origen se encuentra en una de las chimeneas de San Simeón, que como la de Xanadú adolecía de falta de

5. Id. ib., p. 77.

6. Id. ib., p. 80. Según Carringer, tiene su origen en San Simeón. 
rigor. Tiene elementos artísticos de distinta procedencia. La boca de la chimenea está compuesta por un arco conopial o tudor, cuya base descansa sobre soportes de proporciones achaparradas que terminan en capiteles de decoración antropomórfica, estilísticamente cercanos al románico. Rodea el arco una cuerda trenzada, muy gruesa, pudiéndose tratar del cordón franciscano o nudo náutico, motivo ornamental usado con frecuencia en la arquitectura hispanoamericana y relacionable otra vez con la ubicación de Xanadú. El manto de la chimenea está recorrido por una trama romboidal ocupada por una decoración que puede tratarse tanto de la flor de lis como de armiños - los armiños aparecen en el escudo de los Tudor antes de su llegada al trono de Inglaterra y la flor de lis tras su subida al trono-. Esto nos lleva a relacionar este motivo con la boca de la chimenea. Se corona con una escultura ecuestre de estilo gótico, lo que hace que la parte superior de la chimenea tenga semejanza formal y estructural con la de la sepultura del duque Bréze de la catedral de Rouen.

Reutilizada de un filme anterior, la escalera del gran salón de Xanadú tiene dos tramos y está recorrida por esculturas de procedencia egipcia y grecorromana, apareciendo la balaustrada sólo en el rellano superior. La escalera parece tener su punto de partida en la serie de escalas barrocas ${ }^{7}$ que inauguró Juvara en el palacio Madama de Turín y en el Palacio Real de Madrid y continuó Vanvitelli en la Scala Regia del Palacio Real de Caserta, y es que el gran salón en general y la escalera en particular comparten con el barroco la monumentalidad, la espacialidad y el gusto por lo grandioso, generando un sentido de lo escenográfico que, ayudado por los contrastes entre luces y sombras, crea un marco o escena donde se mueven los personajes. Pero también tienen en común con lo barroco el gusto por lo caprichoso, lo extravagante, lo extraño, la exageración y la búsqueda de la perspectiva, tema que preocupó tanto en el barroco y que aquí se salva mediante la profundidad de campo, la iluminación y los telones negros colocados en el fondo. De esta forma se conseguía un ilusionismo, un engaño visual que, por otra parte, entra también dentro de las características barrocas.

El eclecticismo continúa al colocar en el mismo salón una portada gótica junto a otra trapezoidal y con estípites, creando un estilo indeterminado.

Fuera ya del gran salón, en el pasillo que une las habitaciones privadas con la escalera, predomina "lo árabe"; aunque no un estilo puro, sino un pastiche pasado por Hollywood. Es más una evocación a este estilo: los arcos lobulados con

7. Id. ib. Carringer en la página 76 asegura: "Un término clave en el guión es renacentista. La biblioteca del departamento de arte de la RKO tenía un libro conocido, The Architecture of the Renaissance in Italy, de William J. Anderson..." y en la página 79: "El prototipo visual de este nuevo diseño (se refiere a la escalera) pudo haber sido de nuevo la obra de Anderson La arquitectura del Renacimiento en Italia, a la que pertenece la ilustración inferior". Sin embargo, la ilustración que aparece en el libro de Carringer no es otra que la escalera del Palacio Madama de Turín, su error está en incluir dentro del renacimiento el primer barroco. 
alfiz mudéjar descansan sobre capiteles flamígeros, fruto de la imaginación de algún miembro del departamento de arte.

En el interior de Xanadú, como en el exterior, no se trataba de representar fidedignamente un estilo artístico, sino de utilizarlos como un elemento más dentro del lenguaje cinematográfico. De todas formas, todo esto se acepta de forma natural cuando se ve el filme dado el capital de Kane, pero al mismo tiempo da pistas sobre su personalidad extravagante y su deseo de ir contracorriente.

Tras el abandono de Xanadú por parte de Susan, vemos la figura de Kane atravesando el pasillo: su imagen, enmarcada en los arcos lobulados, se multiplica en los espejos en busca de su identidad. Años más tarde, Orson Welles repetirá un efecto similar en La dama de Shanghai (The lady of Shanghai, 1947).

En la parte final de Ciudadano Kane se nos intenta transmitir lo que siente un hombre solitario y abatido al final de su vida, cuando sólo le queda esperar la muerte. Desde este punto de vista podemos comparar, metafóricamente, a Xanadú con una tumba, y es que en el filme se ha recurrido a una serie de elementos para crear esta idea: la luz dura y el teatral maquillaje en el rostro de Kane le hacen parecer un moribundo, las ráfagas de luz recaen sobre la arquitectura y las esculturas figurando una atmósfera fantasmagórica, e incluso aparecen objetos materiales en cierto sentido relacionables con la muerte: la vidriera gótica y la planta rectangular del gran salón -elementos que evocan una iglesia-, el uso del mármol y el sepulcro situado a la izquierda de la escalera. Siguiendo con este aspecto, encontramos constantes referencias a Egipto y, en consecuencia, al deseo de eternidad más allá de la muerte: la mención a los faraones y a las pirámides en el noticiario; el hieratismo de la postura de Kane, mientras recorre lentamente la sala con los brazos pegados al cuerpo, repite la figura de una de las esculturas egipcias que le rodean. Los faraones elevaron gigantescos bloques de piedra para que les sirvieran de morada eterna en los que descansarían rodeados de sus fabulosos tesoros. Xanadú es le mausoleo donde Kane, acompañado de sus pertenencias, reposa aun antes de morir. Tras la muerte de Kane, el castillo, sellado como una tumba egipcia, guarda en su interior el secreto de "Rosebud" y el misterio de la personalidad de Charles Foster Kane.

Buscando posibles antecedentes del eclecticismo arquitectónico de Ciudadano Kane, Robert L. Carringer los halla en el cine de Griffith y De Mille, y no encuentra ninguno en la historia del arte ${ }^{8}$.

Es evidente que en algunos de los filmes de David W. Griffith como Judith de Betulia (Judith of Betulia, 1913) o Intolerancia (Intolerance, 1916) o en los de Cecil B. De Mille, como en Los diez mandamientos (The ten commandments,

8. Id. ib., p. 77. 
1923), aparece una arquitectura que participa de lo ecléctico y lo monumental, pero circunscribir estas características a estos ejemplos es excesivo, ya que esto ha sido algo común a muchas de las producciones históricas anteriores a 1941: la italiana Cabiria, de 1913; las americanas Cleopatra, de 1917; La reina de Sheba (Queen of Sheba, 1921); El arca de Noé (Noah's Ark, 1928); las versiones de El ladrón de Bagdad (The thief of Bagdad) de 1924 y $1939 \ldots$ era un cine que buscaba el colosalismo como forma de expresión para crear un gran espectáculo con grandes escenografías que consiguieran asombrar al espectador. El eclecticismo de sus decorados viene dado por este afán de grandeza y por ello no importaba unir de forma delirante los más diversos estilos artísticos.

Sin embargo, el caso de Ciudadano Kane es distinto. Es cierto que se usa el eclecticismo en los decorados y que éstos gozan de una gran monumentalidad; pero esto no es un fin en sí mismo, sino que es un medio para simbolizar de forma abstracta un personaje. En este sentido, Ciudadano Kane se acerca más al expresionismo alemán, donde se usaban los decorados para marcar el carácter y los sentimientos de los personajes, tal es el caso de filmes expresionistas como Raskolnikov (1923), Las manos de Orlac (Orlacs Hände, 1924) ${ }^{9}$, o El gabinete del Dr. Caligari (Das kabinett del Dr. Caligari, 1929), todas dirigidas por Robert Wiene. En el expresionismo no sólo los decorados fueron utilizados para acentuar dramáticamente a los personajes, sino también los complicados movimientos y encuadres de la cámara. Igualmente, la dirección y la calidad de la luz (altos contrastes entre luces y sombras). Todo lo cual fue repetido por Ciudadano Kane, incluyendo la elección de la fotografía en blanco y negro que favorecía el claro-oscuro.

Siguiendo con esta idea sería interesante mencionar los filmes de terror producidos por la Universal en la década de los treinta, cintas como Drácula (1931), El caserón de las sombras (The old dark house, 1932) o La torre de Londres (The tower of London, 1939), por citar algunas en las que, como en Ciudadano Kane, los sentimientos de los personajes se distinguían por el maquillaje, el vestuario y la iluminación, y el escenario era determinante para la trama. En ellos se recreaba un ambiente gótico mediante elementos arquitectónicos que también aparecen en Xanadú: el salón noble, escaleras, chimeneas, candelabros, criptas ${ }^{10}$, puertas y ventanas góticas e incluso castillos o mansiones sobre montañas "I.

9. La versión americana de Las manos de Orlacs (Mad Love, 1935) fue fotografiada por Greg Toland, operador de Ciudadano Kane.

10. En el guión original de Ciudadano Kane se incluía una escena, eliminada posteriormente, en el interior de la capilla de Xanadú.

11. Tal es el caso de Drácula (1930), Frankenstein (1931) o La novia de Frankenstein (The bride of Frankenstein, 1932), además esta última comenzaba con un rápido travelling que nos acercaba a una gótica mansión sobre una montaña. 
En cuanto a que no existen modelos históricos para la mescolanza de estilos de Xanadú, Robert L. Carringer parece olvidar el eclecticismo arquitectónico del tercer cuarto del siglo XIX, donde no se creó un nuevo arte, sino que se intentaba componer un todo surgido de la mezcla de distintos estilos de épocas anteriores.

Aunque tampoco hay que viajar tanto en el espacio y en el tiempo en busca del eclecticismo en la arquitectura real. Desde los comienzos de la cinematografía, las ciudades de América se poblaron de lo que se vino a llamar "los palacios del cine" o "templos del teatro silencioso". Florecieron locales de cine como el Regent (1913) en Nueva York, el Houston Majestic (1923) o el Ohio Theatre (1928), convirtiéndose la mezcla de estilos en una norma a seguir, predominando en ellos el sabor de lo "exótico": estilos "españoles" (neobarroco colonial, plateresco o morisco) -presentes en Xanadú- y orientales en general ${ }^{12}$; aunque también aparecían otros como renacimiento, barroco o art-decó.

La verdadera originalidad de la arquitectura de Xanadú no reside en su eclecticismo, sino en haber comprendido que Xanadú tenía que ser el símbolo de Kane. Quizás por esto Xanadú haya conseguido entrar en la mitología cinematográfica por sí mismo y envuelto en la leyenda ocupa un lugar predominante frente a los no menos míticos: Shangri-la, Manderley, Tara o Dragonwick.

12. RAMÍREZ, Juan Antonio: La arquitectura en el cine: Hollywood. la Edad de oro. Hermann Blume, Madrid, 1986. 